\title{
MELD Score as a Predictor of Treatment Response of 'Difficult to Treat' Chronic HCV Patients
}

\author{
Taghrid Mohamed Abdalla ${ }^{1}$, Sameh M. Abdel Monem ${ }^{1}$ \\ and Mahmoud Labib Salim ${ }^{2}$ \\ ${ }^{I}$ Tropical Medicine Department, Faculty of Medicine, Zagazig University, Egypt. \\ ${ }^{2}$ Viral Hepatitis Treatment Unit, Al Ahrar Teaching Hospital, Zagazig, Egypt.
}

Corresponding Author

Taghrid Mohamed

Abdalla

Mobile:

00201014616211

E mail:

tagkomy@gmail.com

Key words:

hepatitis C, MELD,

Child score, antiviral
Background and study aim: The introduction of direct acting antiviral agents shifted the management of chronic hepatitis $\mathrm{C}$ virus (HCV) infection to a new level. Pretreatment predictors of benefit are needed to help the selection of patients for treatment. The aim of this work is to study if Model for End Stage Liver Disease (MELD) score can be reliably used as a predictor of response to treatment with direct acting antivirals (DAAs) in 'difficult to treat' chronic HCV patients.

Patients and Methods: This is a retrospective study where files of 91 "difficult to treat" patients were randomly selected from the follow up clinic. Patients' data were collected before and after treatment including history taking, clinical examination, laboratory investigations and abdominal ultrasonography. MELD and Child-Turcotte-Pugh (CTP) scores were calculated.

Results: After treatment, MELD score was significantly improved in $28.6 \%$ of patients, remained stable in $57.1 \%$ and worsened in $14.3 \%$. MELD score was significantly higher among patients with complications than those without complications before and after treatment. No significant difference was detected between patients with and without sustained virologic response (SVR) as regard MELD score changes after treatment.

Conclusion: Baseline MELD score cannot predict the response to treatment of "difficult to treat" chronic HCV patients but can predict the occurrence of complications.

\section{INTRODUCTION}

Chronic hepatitis $\mathrm{C}$ virus (HCV) infection is a major health problem affecting more than 170 million infected individuals worldwide. Liver cirrhosis is a real threat in $2-35 \%$ of the patients after 20-25 years of chronic infection [1]. The classical treatment for $\mathrm{HCV}$ infection was the dual therapy with pegylated interferon (Peg-IFN) $\alpha-2 \mathrm{a}$ or $-2 b$ combined with the guanosine analog ribavirin giving sustained virologic response (SVR) rate of only about $50 \%$ [2]. A new era of direct acting antivirals (DAAs), with SVR rate of about $90 \%$, has emerged. Multiple regimens with various combinations of these drugs, without the use of IFN, proved to be effective and well tolerated, even among patients with advanced liver disease [3].
Despite the poor treatment outcome in patients with decompensated cirrhosis (Child-Pugh B/C) compared to patients with compensated cirrhosis (ChildPugh A), safety issues regarding the use of DAAs among those patients with the most advanced liver disease have arisen [4]. Successful treatment of patients with decompensated liver disease due to HCV has two potential benefits. First, it could result in resolution of complications of endstage liver disease and improve survival resulting in delisting patients awaiting liver transplantation. Second, perhaps successful treatment of HCV could result in better post-transplant outcomes [5].

Decompensation is the presence of at least one complication of end-stage liver disease including but not limited to hepatic encephalopathy, ascites or 
bleeding from esophagogastric varices. [6]. The Model for End-stage Liver Disease (MELD) is a validated chronic liver disease severity scoring system that uses a patient's laboratory values for serum bilirubin, serum creatinine, and the international normalized ratio (INR). In patients with cirrhosis, an increasing MELD score is associated with increasing severity of hepatic dysfunction and the three-month mortality risk [7]. Baseline MELD score can predict the risk of hepatic decompensation during IFN and antiviral therapy helping the decision making in $\mathrm{HCV}$ patients with advanced liver cirrhosis [8]. Several studies revealed improving MELD score after DAAs therapy in some patients with advanced HCV-associated liver cirrhosis $[\mathbf{9 , 1 0 ]}$.

The aim of this work is to study if MELD score can be reliably used for prediction of response to treatment with DAAs in 'difficult to treat' chronic HCV patients.

\section{PATIENTS AND METHODS}

A retrospective cohort study was conducted as a collaborate work between Tropical Medicine Department, Faculty of Medicine, Zagazig University and Viral Hepatitis Treatment Unit, Al Ahrar Teaching Hospital. Ninety- one patients who were selected and categorized as "difficult to treat" were included in this study. Their files were randomly selected from the follow up clinic - in Al Ahrar hospital- till the completion of sample size from July 2017 to January 2018.

\section{Inclusion criteria:}

According to Supreme Council and NCCVH 2016

1. HCV RNA positivity.

2. Age $\geq 18$ years.

Criteria of difficult to treat HCV Patient including one or more of the following:

- Serum albumin $<3.5 \mathrm{~g} / \mathrm{dl}$

- Total serum bilirubin $>1.2 \mathrm{mg} / \mathrm{dl}$
- INR $>1.2$

- Platelet $<150,000 / \mathrm{mm}^{3}$

- PEG-IFN treatment experienced.

- Child A and B classes.

Exclusion criteria:

- Child C cirrhotic patients (Child score $\geq 10$ )

- Platelet count $<50,000 / \mathrm{mm} 3$

- HCC, except 6 months after intervention aiming at cure with no evidence of activity by dynamic imaging (CT or MRI).

- Extra-hepatic malignancy except after two years of disease-free interval.

- Pregnancy or inability to use effective contraception.

- Inadequately controlled diabetes mellitus (HA1C $>9$ ).

\section{Methods:}

Data of all patients were collected before treatment and after 12 weeks of the end of treatment. The data included:

- History.

- Clinical examination.

- Laboratory investigation including complete blood count (CBC), liver function test, international normalized ratio (INR), serum creatinine, Alpha feto protein, HCV RNA PCR and Abdominal ultrasonography.

- After collection of these data MELD and Child-Turcotte- Pugh (CTP) scores were calculated pre and post treatment.

The original mathematical formula for MELD is:

MELD $=3.78 \times \log$ [serum bilirubin $(\mathrm{mg} / \mathrm{dL})]+$ $11.2 \times \log [\mathrm{INR}]+9.57 \times \log$ [serum creatinine $(\mathrm{mg} / \mathrm{dL})]+6.43 \times(0$ if cholestatic or alcoholic $\&$ 1 if others).The score can be calculated on handheld computing devices, and is available at www.mayoclinic.org [11].

Child -Turcotte- Pugh score:

It was calculated according to Brown et al [12]. 
Table (1): Child -Turcotte- Pugh scoring system.

\begin{tabular}{|l|c|c|c|}
\hline \multicolumn{4}{|c|}{ Child-Turcotte-Pugh score } \\
\hline \multirow{2}{*}{ Measurements } & $\underline{3}$ & \multicolumn{2}{|c|}{ Score } \\
\cline { 2 - 4 } & $\underline{\mathbf{1}}$ & $\underline{\mathbf{2}}$ & $\underline{\mathbf{3}}$ \\
\hline Encephalopathy & None & Grade I-II & Grade III-IV \\
\hline Ascites & None & Mild & Moderate to tense \\
\hline Bilirubin (mg/dL) & $1-2$ & $2-3$ & $>3$ \\
\hline Albumin (g/dL) & $>3.5$ & $2.8-3.5$ & $<2.8$ \\
\hline$\underline{\text { INR }}$ & $<1.7$ & $1.7-2.20$ & $>2.20$ \\
\hline
\end{tabular}

Class A: 5-6 points.

Class B: 7-9 points.

Class C: $10-15$ points

Treatment regimen of "difficult to treat group" is Sofosbuvir (400 mg)/ day + Daclatasvir (60mg)/ day + Ribavirin for 12 weeks. The starting dose of ribavirin is $600 \mathrm{mg} /$ day. Trials were done to reach a dose of $1000 \mathrm{mg} /$ day based on the individual patient tolerability.

\section{Statistical analysis}

Data were checked, entered and analyzed using SPSS 15 for Windows. Data were expressed as mean \pm SD for quantitative variable, number and percentage for qualitative one. Chi-square (X2) or $\mathrm{t}$ test, paired $\mathrm{t}$ test, McNemar's test or StuartMaxwell test were used when appropriate. $\mathrm{P}<0.05$ was considered significant. $\mathrm{P}<0.001$ was considered high significant.

\section{RESULTS}

Ninety- one patients who were categorized as "difficult to treat" were included in this study. Their files were selected randomly from the follow up clinic till the completion of sample size from July 2017 to January 2018.

$59.3 \%$ of patients were males and $40.7 \%$ were females. The mean age was $53.52(53.52 \pm 8.48)$ years and $11 \%$ only had prior HCV treatment. AFP level was $23.90 \pm 18.40 \mathrm{ng} / \mathrm{ml}$ and $\mathrm{HCV}$ RNA level was $6.35 \pm 4.17$ million IU/ml (Table 2).
After treatment, MELD score improved in about $28.6 \%$ of patients, remained stable in $57.1 \%$ and worsen in $14.3 \%$ (Table 3 ).

There was no significant difference in the mean values of MELD score between patients with and without SVR before treatment and also after treatment (Table 4).

MELD score was improved in $27.9 \%$ of patients who had SVR. Despite that $40 \%$ of patients without SVR showed improvement of their MELD scores. There were no significant differences between both groups regarding percentage of improved, stable and worsen cases (Table 5).

MELD score's mean was higher among patients with complications when compared with those without complications before and after treatment with significant statistical differences. The patient without complications showed highly significant decrease in their mean MELD after treatment, while patients with complications showed nonsignificant increase of their mean MELD score. Five patients $(5.5 \%)$ were complicated by variceal bleeding (one case), hepatic encephalopathy grade 2 (one case) and HCC (one case) (Table 6).

In patients without complications, MELD scores were improved in $30.2 \%$ and worsen in about $10.5 \%$, while in patients with complications; MELD scores did not improve in any one and worsen in $80 \%$ with highly significant difference (Table 7). 
Table (2): Basic characteristics of the studied patients

\begin{tabular}{|c|c|c|}
\hline \multirow[t]{2}{*}{ Demographic data } & \multicolumn{2}{|c|}{$\begin{array}{l}\text { All patients } \\
(\mathbf{N}=91)\end{array}$} \\
\hline & No. & $\%$ \\
\hline \multicolumn{3}{|l|}{ Gender } \\
\hline Male & 54 & $59.3 \%$ \\
\hline Female & 37 & $40.7 \%$ \\
\hline \multicolumn{3}{|l|}{ Age (years) } \\
\hline Mean \pm SD & \multicolumn{2}{|c|}{$53.52 \pm 8.48$} \\
\hline Median (range) & \multicolumn{2}{|c|}{$56(29-67)$} \\
\hline \multicolumn{3}{|l|}{ AFP (ng/ml) } \\
\hline Mean \pm SD & \multicolumn{2}{|c|}{$23.90 \pm 18.40$} \\
\hline Median (range) & \multicolumn{2}{|c|}{$17(8-97)$} \\
\hline \multicolumn{3}{|l|}{$\mathrm{HCV}$ RNA $\left(\times 10^{6} \mathrm{iu} / \mathrm{ml}\right.$} \\
\hline Mean \pm SD & \multicolumn{2}{|c|}{$6.35 \pm 4.17$} \\
\hline Median (range) & \multicolumn{2}{|c|}{$6(1-17)$} \\
\hline \multicolumn{3}{|l|}{ Prior HCV treatment } \\
\hline No & 81 & $89 \%$ \\
\hline Yes & 10 & $11 \%$ \\
\hline
\end{tabular}

AFP: Alpha fetoprotein

Table (3): Change in MELD score among the studied patients

\begin{tabular}{|l|c|c|}
\hline \multirow{2}{*}{ Change in MELD score } & \multicolumn{2}{|c|}{ All patients (N=91) } \\
\cline { 2 - 3 } & No. & \% \\
\hline Improved & 26 & $28.6 \%$ \\
\hline-4 & 1 & $1.1 \%$ \\
\hline-3 & 12 & $13.2 \%$ \\
\hline-2 & 11 & $12.1 \%$ \\
\hline-1 & 2 & $2.2 \%$ \\
\hline Stable & 52 & $57.1 \%$ \\
\hline Worsened & 13 & $14.3 \%$ \\
\hline+1 & 7 & $7.7 \%$ \\
\hline+2 & 6 & $6.6 \%$ \\
\hline
\end{tabular}

Table (4): Comparison between patients with and without SVR as regard pre- and post-treatment MELD score's mean

\begin{tabular}{|c|c|c|c|c|}
\hline MELD score & $\begin{array}{c}\text { With SVR } \\
(\mathrm{N}=86)\end{array}$ & $\begin{array}{l}\text { Without SVR } \\
\qquad(\mathrm{N}=5)\end{array}$ & Test & P-value \\
\hline \multicolumn{5}{|l|}{ Pre-treatment score } \\
\hline Mean \pm SD & $14.72 \pm 2.06$ & $15.60 \pm 3.13$ & \multirow[t]{2}{*}{-0.915} & \multirow{2}{*}{$\begin{array}{l}0.360 \\
(\mathrm{NS})\end{array}$} \\
\hline Median (range) & $15(11-20)$ & $17(11-19)$ & & \\
\hline \multicolumn{5}{|l|}{ Post-treatment score } \\
\hline Mean \pm SD & $14.23 \pm 2.09$ & $15 \pm 3.67$ & \multirow[t]{2}{*}{-0.390} & \multirow{2}{*}{$\begin{array}{r}0.697 \\
(\mathrm{NS})\end{array}$} \\
\hline Median (range) & $14(11-22)$ & $14(11-21)$ & & \\
\hline Test• & -3.394 & -0.816 & & \\
\hline p-value (Sig.) & $0.001 *$ & $0.414(\mathrm{NS})$ & & \\
\hline
\end{tabular}

Abdalla et al., Afro-Egypt J Infect Endem Dis 2019; 9(1):87-93

https://aeji.journals.ekb.eg/

http://mis.zu.edu.eg/ajied/home.aspx 
Table (5): Comparison between patients with and without SVR as regard MELD score changes after treatment

\begin{tabular}{|c|c|c|c|c|c|c|}
\hline \multirow[t]{2}{*}{ MELD score change } & \multicolumn{2}{|c|}{$\begin{array}{c}\text { With SVR } \\
(\mathrm{N}=86)\end{array}$} & \multicolumn{2}{|c|}{$\begin{array}{c}\text { Without SVR } \\
(\mathrm{N}=5)\end{array}$} & \multirow[t]{2}{*}{ Test: } & \multirow[t]{2}{*}{ P-value } \\
\hline & No. & $\%$ & No. & $\%$ & & \\
\hline Improved & 24 & $27.9 \%$ & 2 & $40 \%$ & \multirow[t]{3}{*}{0.635} & \multirow{3}{*}{$\begin{array}{c}0.728 \\
\text { (NS) }\end{array}$} \\
\hline Stable & 50 & $58.1 \%$ & 2 & $40 \%$ & & \\
\hline Worsen & 12 & $14 \%$ & 1 & $20 \%$ & & \\
\hline-4 & 1 & $1.2 \%$ & 0 & $0 \%$ & \multirow[t]{7}{*}{2.756} & \multirow{7}{*}{$\begin{array}{c}0.839 \\
\text { (NS) }\end{array}$} \\
\hline-3 & 11 & $12.8 \%$ & 1 & $20 \%$ & & \\
\hline-2 & 10 & $11.6 \%$ & 1 & $20 \%$ & & \\
\hline-1 & 2 & $2.3 \%$ & 0 & $0 \%$ & & \\
\hline 0 & 50 & $58.1 \%$ & 2 & $40 \%$ & & \\
\hline+1 & 7 & $8.1 \%$ & 0 & $0 \%$ & & \\
\hline+2 & 5 & $5.8 \%$ & 1 & $20 \%$ & & \\
\hline
\end{tabular}

$\$$ Chi-square test.

NS significant.

Table (6): Comparison between patients with and without complications as regard pre- and posttreatment MELD score's mean

\begin{tabular}{|c|c|c|c|c|}
\hline MELD score & $\begin{array}{l}\text { Without complications } \\
(\mathbf{N}=\mathbf{8 6})\end{array}$ & $\begin{array}{c}\text { With complications } \\
(\mathrm{N}=5)\end{array}$ & Test & P-value \\
\hline \multicolumn{5}{|l|}{ Pre-treatment } \\
\hline Mean \pm SD & $14.59 \pm 2$ & $17.80 \pm 1.92$ & \multirow[t]{2}{*}{-2.859} & \multirow{2}{*}{$\begin{array}{c}0.004 \\
*\end{array}$} \\
\hline Median (range) & $14(11-20)$ & $18(15-20)$ & & \\
\hline \multicolumn{5}{|l|}{ Post-treatment } \\
\hline Mean \pm SD & $13.98 \pm 1.78$ & $19.20 \pm 2.68$ & \multirow[t]{2}{*}{-3.428} & \multirow{2}{*}{$\begin{array}{c}0.001 \\
*\end{array}$} \\
\hline Median (range) & $14(11-19)$ & $19(15-22)$ & & \\
\hline Test• & -4.011 & -1.890 & & \\
\hline P-value & $<0.001 * *$ & 0.059 (NS) & & \\
\hline
\end{tabular}

$\$$ Mann Whitney U test. $\bullet$ Wilcoxon signed ranks test *significant.

**highly significant. NS non- significant.

Table (7): Comparison between patients with and without complications as regard MELD score changes after treatment

\begin{tabular}{|c|c|c|c|c|c|c|}
\hline \multirow{2}{*}{$\begin{array}{l}\text { MELD score } \\
\text { change }\end{array}$} & \multicolumn{2}{|c|}{$\begin{array}{l}\text { Without complications } \\
(\mathrm{N}=86)\end{array}$} & \multicolumn{2}{|c|}{$\begin{array}{c}\text { With complications } \\
(\mathrm{N}=5)\end{array}$} & \multirow[t]{2}{*}{ Test } & \multirow[t]{2}{*}{ P-value } \\
\hline & No. & $\%$ & No. & $\%$ & & \\
\hline Improved & 26 & $30.2 \%$ & 0 & $0 \%$ & \multirow[t]{3}{*}{18.782} & \multirow{3}{*}{$\begin{array}{c}<0.001 \\
* *\end{array}$} \\
\hline Stable & 51 & $59.3 \%$ & 1 & $20 \%$ & & \\
\hline Worsen & 9 & $10.5 \%$ & 4 & $80 \%$ & & \\
\hline-4 & 1 & $1.2 \%$ & 0 & $0 \%$ & \multirow[t]{7}{*}{26.718} & \multirow{7}{*}{$\begin{array}{l}<0.001 \\
* *\end{array}$} \\
\hline-3 & 12 & $14 \%$ & 0 & $0 \%$ & & \\
\hline-2 & 11 & $12.8 \%$ & 0 & $0 \%$ & & \\
\hline-1 & 2 & $2.3 \%$ & 0 & $0 \%$ & & \\
\hline 0 & 51 & $59.3 \%$ & 1 & $20 \%$ & & \\
\hline+1 & 6 & $7 \%$ & 1 & $20 \%$ & & \\
\hline+2 & 3 & $3.5 \%$ & 3 & $60 \%$ & & \\
\hline
\end{tabular}

$\ddagger$ Chi-square test. $\quad * *$ highly significant. 


\section{DISCUSSION}

Chronic hepatitis $\mathrm{C}$ virus infection is a major health issue worldwide. It is the leading cause of liver-related morbidity and mortality in Egypt and one of the most common indications for liver transplantation [13]. Pretreatment predictors of benefit are needed to guide patient selection for therapy and, more importantly, identify a group of patients in whom therapy is useless and who should undergo liver transplantation and DAAs therapy post- transplantation [14].

This retrospective study was planned to find the value of MELD score to predict the response and complications after DAAs therapy in "difficult to treat" chronic HCV patients.

MELD score improved in $28.6 \%$ of patients worsened in $14.3 \%$ and remain stable in $57.1 \%$. Deterding et al. studied 80 patients with advanced HCV associated liver cirrhosis of genotypes 1, 2, 3 and 4 receiving different combinations of DAAs. MELD scores improved until post-treatment week 12 in $44 \%$ of the patients, remained stable in $41 \%$ and worsened in $15 \%$ and CPT scores improved in $25 \%$ of patients [9]. Foster et al. reported changes in MELD score 4 weeks after the cessation of DAAs therapy in advanced $\mathrm{HCV}$-associated liver cirrhosis patients where $47.7 \%$ had no significant change, $41.8 \%$ improved by $\geq 2$ points; and $10.5 \%$ worsened by $\geq 2$ points [10]. In another retrospective, national, multicenter study in patients from the Spanish Hepa-C registry investigated the effectiveness and safety of all currently approved DAAs regimens in patients with advanced liver disease, including those with decompensated cirrhosis. Overall, 36\% showed improvements in MELD score, $31 \%$ had no change and 33\% worsened [15]. All these results are suggesting that eradication of the virus can improve hepatic function rapidly by attenuating the injury and inflammation caused by $\mathrm{HCV}$ replication.

In this study, before treatment, mean MELD score in patients who reported complications during treatment was significantly higher when compared with patients without complications indicating that the high MELD score is a predictor of occurrence of complication. However, because of the small number of patients with complications $(n=5)$, the exact predictive cutoff value of MELD cannot be calculated by the specific statistical tests used for this purpose. A similar result was reported by Manns et al. who observed that the patients with baseline MELD score $<15$ reported more improvement of their MELD after treatment and rarely develop complications while those who had baseline MELD score $\geq 15$ were in the opposite side [16].

In this study, one patient was reported to develop hepatocellular carcinoma (HCC) after treatment. Although DAAs may improve liver function parameters in chronic HCV patients, HCC may still develop. It is well established that $\mathrm{HCC}$ can occur after interferon-induced SVR even if the relative HCC risk is reduced [17]. Deterding et al. observed five cases of HCC in 80 cirrhotic patients treated with DAAs and followed up for only 6-9 months highlighting the need for careful monitoring even if HCV RNA is negative [9].

In this study, before treatment, mean MELD score in patients who achieved SVR didn't show significant difference when compared with patients who didn't achieve SVR indicating that MELD score cannot be used as a predictor of response to DAAs. This result can be explained by the significant decrease in the mean MELD score in patients with SVR and the unchanged score of patients without SVR after treatment. This result is not matching with that of Carrillo et al. who reported that decompensated cirrhosis (CTP B/C) at baseline was associated with lower rates of virologic response compared with patients with less advanced cirrhosis (CTP A). Carrillo and his colleague put Child B/C patients in one group leading to decreased response rate of this group. In addition, $67 \%$ of Child B patients in that study had score 7 which is the nearest score to Child A making those to achieve high SVR rate near to that of Child A [15].

\section{CONCLUSION}

Baseline MELD score cannot predict the response to treatment of 'difficult to treat' chronic HCV patients but can predict the occurrence of complications.

\section{Ethical approval:}

The research protocol was approved by the Institutional Review Board (IRB), the ethical committee of Zagazig University Hospitals.

Funding: None.

\section{Conflicts of interest: None.}

\author{
Abdalla et al., Afro-Egypt J Infect Endem Dis 2019; 9(1):87-93 \\ https://aeji.journals.ekb.eg/ \\ http://mis.zu.edu.eg/ajied/home.aspx
}




\section{REFERENCES}

1- Seef LB: Natural history of chronic hepatitis C. Hepatology; 2002, 36(1): S35-S 46.

2- Fried MW, Shiffman ML, Reddy KR, Smith C, Marinos G, Gonçales FL Jr, et al.: Peg-interferon alfa-2a plus ribavirin for chronic hepatitis $\mathrm{C}$ virus infection. N Engl J Med; 2002, 347(13): 975-82.

3- EASL Clinical Practice Guidelines: management of hepatitis C virus infection. J Hepatol ;55: 24564. Hepatitis C. Aliment Pharmacol Ther; 2015, 34:297-305.

4- Saxena V, Nyberg L, Pauly M, Dasgupta A, Nyberg A, Piasecki B, et al.: Safety and efficacy of simeprevir/sofosbuvir in hepatitis C-infected patients with compensated and decompensated cirrhosis. Hepatology; 2015, 62(3): 715-25.

5- Berenguer M, Ferrell L, Watson J, Prieto M, Kim M, Rayón M, et al.: HCV-related fibrosis progression following liver transplantation: increase in recent years. $J$ Hepatol; 2000, 32(4):673-84.

6- Martina Gambato, Sabela Lens, Miquel Navasa and Xavier Forns: Treatment options in patients with decompensated cirrhosis, pre- and posttransplantation. J Hepatol; 2014, 61(1):S120-31.

7- Freeman RB Jr, Wiesner RH, Harper A, McDiarmid SV, Lake J, Edwards E, et al.: The new liver allocation system: moving toward evidence-based transplantation policy. Liver Transplant; 2002, 8(9):851-54.

8- Georg Dultz, Martin Seelhof, Eva Herrmann, Martin-Walter Welker, Mireen Friedrich-Rust, Gerlinde Teuber, al.: Baseline MELD score predicts hepatic decompensation during antiviral therapy in patients with chronic hepatitis $\mathrm{C}$ and advanced cirrhosis. PLOS ONE www.plosone.org; 2013, 8 (8): e71262.

9- Deterding K, Höner Zu Siederdissen C, Port K, Solbach P, Sollik L, Kirschner J, et al.: Improvement of liver function parameters in advanced HCV-associated liver cirrhosis by IFNfree antiviral therapies. Aliment Pharmacol Ther; 2015, 42(7): 889-901.
10- Foster GR, Irving WL, Cheung MC, Walker AJ, Hudson BE, Verma S, et al.: Cohort study of the impact of direct acting antiviral therapy in patients with chronic hepatitis C and decompensated cirrhosis. J Hepatol;2016, 64(6): 1224-31.

11- Kamath PS, Wiesner RH, Malinchoc M, Kremers W, Therneau TM, Kosberg CL, et al.: A model to predict survival in patients with end-stage liver disease. Hepatology; 2001, 33(2): 464-70.

12- Robert S. Brown, Jr, K. Shiva Kumar, Mark W. Russo, Milan Kinkhabwala, Dianne L. Rudow, Patricia Harren, et al.: Model for end-stage liver disease and Child-Turcotte-Pugh score as predictors of pre transplantation disease severity, post transplantation outcome, and resource utilization in United Network for Organ Sharing status 2A patients. Liver Transplant; 2002, 8(3): 278-84.

13- Gower E, Estes C, Blach S, Razavi-Shearer K and Razavi H: Global epidemiology and genotype distribution of the hepatitis $\mathrm{C}$ virus. $J$ Hepatol; 2014, 61(1):S45-S57.

14- Elsharkawy A, El-Raziky M, El-Akel W, ElSaeed K, Eletreby R, Hassany M, et al.: Planning and prioritizing direct-acting antivirals treatment for HCV patients in countries with limited resources: lessons from the Egyptian experience. J Hepatol ; 2018, 68(4):691-698.

15- Fernández Carrillo C, Lens S, Llop E, Pascasio JM, Crespo J, Arenas J, et al.: Treatment of hepatitis $\mathrm{C}$ virus infection in patients with cirrhosis and predictivevalue of MELD: Analysis of data from the Hepa-C registry. Hepatology; 2017, 65(6):1810-22.

16- Manns M, Samuel D, Gane EJ, Mutimer D, McCaughan G, Buti M, et al.: Ledipasvir and sofosbuvir plus ribavirin in patients withgenotype 1 or 4 hepatitis $\mathrm{C}$ virus infection and advanced liverdisease: a multicentre, open-label, randomised, phase 2 trial. Lancet Infect Dis; 2016, 16(6): 685-97.

17- van der Meer AJ, Veldt BJ, Feld JJ, Wedemeyer H, Dufour JF, Lammert F, et al.: Association between sustained virological response and allcause mortality among patients with chronic hepatitis $\mathrm{C}$ and advanced hepatic fibrosis. JAMA; 2014, 308(24):2584-93. 